\title{
Is endometrial infection with Candida albicans a cause of recurrent vaginal thrush?
}

\author{
J R Smith, C Wells, M Jolly, P Shah, M Savage, P Reginald, V S Kitchen
}

\begin{abstract}
Objective-It was hypothesised that the endometrium might act as a resevoir for candida, thus infecting the vagina as the endometrium is shed during menstruation.

Design-A prospective study of women with recurrent vulvo-vaginal candidiasis. The endometrium was sampled and cultured for candida species.

Setting-Central London STD clinic. Subjects-26 women were enrolled, of whom 20 completed the study.

Results-One patient had a positive endometrial culture for candida species, the isolate being Candida krusei.

Conclusions-The endometrium is not a common resevoir for candida species and therefore, infection at this site is an unlikely cause of recurrent vaginal candidiasis.
\end{abstract}

(Genitourin Med 1993;69:295-296)

\section{Introduction}

Candida albicans was incidentally found as a contaminant in endometrial cell cultures obtained at hysterectomy and in endometrial cell cultures obtained from endometrial aspiration. It was thought that although contamination of the endometrium could have occurred whilst performing an endometrial aspirate, this was much less likely in a hysterectomy specimen.

Common predisposing factors to vaginal candidiasis are humidity, hormonal influences including pregnancy, and diabetes mellitus. Other factors include immunosuppression, and removal of bacterial inhibitors usually from the recurrent or prolonged use of antibiotics. ${ }^{1}$ Reinfection can occur from sexual partners ${ }^{2}$ and in cases of recurrence these commonly occur pre- and perimenstrually. ${ }^{3}$ Confusion exists in the literature as to why $C$ albicans infection should be more common perimenstrually. Vaginal $\mathrm{pH}$ is thought to rise in the luteal and menstrual phases of the menstrual cycle ${ }^{4}$ and since vulvo-vaginal candidiasis is commoner at this time, ${ }^{3}$ there has been thought to be an association between the two. However, the association of a $\mathrm{pH}$ of $<4.5$ as an indicator of vaginal candidiasis is well known. ${ }^{5}$ This discrepancy coupled with the finding of candidal contamination in endometrial cell cultures led to the hypothesis that the endometrium might be acting as a resevoir for $C$ albicans which is carried into the vagina during menstruation causing recurrences of vaginal candidiasis.

It was hypothesised that if the endometrium were acting as resevoir for candida species, this could explain the increased efficacy of oral fluconazole over topical therapy in the treatment of recurrent vaginal candidiasis. $^{6}$

\section{Methods}

Patients were considered for enrollment if they had symptoms suggestive of vaginal candidiasis and a documented history of recurrent vaginal candidiasis in the preceding year. A full STD screen comprising syphilis serology, urethral and cervical swabs for Gram stain and culture of $N$ gonorrhoeae, enzyme linked immunosorbent assay for $C$ trachomatis, and microscopy for $T$ vaginalis, bacterial vaginosis and $C$ albicans was performed. Patients were excluded from the study if infection with $N$. gonorhoeae, C. trachomatis, $T$. vaginalis, or bacterial vaginosis was detected. If vaginal candidiasis was confirmed, the patient was considered eligible for enrollment. Study patients were pre-treated with vaginal clotrimazole in a single $500 \mathrm{mg}$ dose in order to lessen the risk of contamination of the endometrial sample with candida species via the cervical canal. The patients were advised not to have sexual intercourse for the duration of the study.

One week later patients were reviewed and a further full STD screen performed. High vaginal, rectal and endocervical swabs were taken for candida and a urinary Beta HCG pregnancy test performed to exclude pregnancy. Thereafter, the vagina was irrigated with $20 \mathrm{mls}$ saline and the resulting suspension sent for microscopy and culture. The endometrium was then aspirated transcervically using a Pipelle.

The patients were then retreated with either a repeat dose of clotrimazole or oral fluconazole in a single dose of $500 \mathrm{mg}$ and $150 \mathrm{mg}$ respectively. The STD screen, candidal specimen collection and endometrial aspiration were then repeated one week later.

The candidal specimens obtained from the high vagina, endocervix, rectum and from vaginal aspiration were innoculated onto culture plates of Sabouraud's agar with chloramphenicol (SC). Growth was graded from $+1-$ to +++ . Of the $20 \mathrm{ml}$ of saline suspension aspirated from the vagina, $0.2 \mathrm{ml}$ was spread over the surface of SC plates. A 1/10 dilution of the suspension was also made, 
Results of candida species detection, in those patients who had endometrial sampling performed

\begin{tabular}{|c|c|c|c|c|c|}
\hline Patient & Rectal & $E C S$ & HVS & Wash CFU & Endomet. \\
\hline 1 Visit 2 & 0 & 0 & 0 & Ca150 & 0 \\
\hline Visit 3 & 0 & $\mathrm{Ck}++$ & $\mathrm{Ck}+++$ & Ck1500 & Ck210 \\
\hline 2 Visit 2 & $\mathrm{Ca}+1-$ & 0 & $\mathrm{Ca}+1-$ & 0 & 0 \\
\hline Visit 3 & 0 & 0 & 0 & 0 & 0 \\
\hline 3 Visit 2 & 0 & 0 & 0 & 0 & 0 \\
\hline Visit 3 & 0 & $\mathrm{Ca}++$ & $\mathrm{Ca}++$ & $\mathrm{Ca} 250$ & 0 \\
\hline 4 Visit 2 & $\mathrm{Ca}+++$ & 0 & $\mathrm{Ca}+$ & $\mathrm{Ca} 360$ & 0 \\
\hline Visit 3 & 0 & 0 & 0 & 0 & 0 \\
\hline 5 Visit 2 & 0 & 0 & 0 & Calo & 0 \\
\hline Visit 3 & 0 & 0 & 0 & 0 & 0 \\
\hline 6 Visit 2 & $\mathrm{Ca}++$ & $\mathrm{Ca}++$ & $\mathrm{Ca}++$ & $\mathrm{Ca} 200$ & 0 \\
\hline Visit 3 & - & - & - & - & - \\
\hline 7 Visit 2 & 0 & 0 & 0 & 0 & 0 \\
\hline Visit 3 & 0 & $\mathrm{Ca}+$ & $\mathrm{Ca}++$ & 0 & 0 \\
\hline
\end{tabular}

$(\mathrm{Ca}=C$. albicans, $\mathrm{Ck}=C$. krusei, $-=$ failed to attend

$\mathrm{CFU}=$ colony forming units $/ \mathrm{ml}$, rectal $=$ rectal swab, HVS $=$ high vaginal swab, $\mathrm{ECS}=$ endocervical swab, Wash. = vaginal saline washings, endomet. = endometrial aspirate)

$0.1 \mathrm{ml}$ of which was spread onto an SC plate. The remainder of the suspension was centrifuged for $3 \mathrm{~min}$ at $2500 \mathrm{rpm}$ and the supernatant discarded. The remaining deposit was resuspended in $0.5 \mathrm{ml}$ saline. Of this, $0.1 \mathrm{ml}$ was taken and spread over an SC plate. The Pippelle used to obtain the endometrial sample was washed through with $0.2 \mathrm{ml}$ saline and these specimens were spread over a further SC plate. All plates were incubated at $37^{\circ} \mathrm{C}$ for 48 hours. Counts were expressed as colony-forming units/ml (CFUs).

\section{Results}

Thirty eight women were enrolled and received initial treatment with a Canestan pessary. Twenty six of these women attended one week later for repeat microbiological tests and endometrial sampling. Five patients had $C$ albicans detected at this visit in either the high vagina, endocervix or rectum. None had candidal species on endometrial culture. Of the twenty women who returned for their third visit (Day 14), five had been retreated with clotrimazole and 15 were treated with fluconazole. From the endometrial aspirates obtained on this occasion, one patient had a positive culture for candida species, the isolate being $C$ krusei. The table shows the results for the seven patients who had candidal species detected in one or more sites at the second and third visits.

The STD screen detected no infection with $N$ gonorrhoeae, $C$ trachomatis, $T$ vaginalis, or bacterial vaginosis.

Of the 20 patients who completed the study three admitted to having sexual intercourse without using a condom between the first and second visit, and seven between the second and third visit.

\section{Discussion}

This study suggests that the endometrium is not commonly a resevoir for candida species in patients with recurrent vaginal candidiasis. The one positive candidal isolate was $C$ krusei found at a higher count in the vagina than in the endometrium, the failure to remove candida from the vagina raises the high possibility of endometrial contamination, via the transcervical route. The double lumen endometrial sampling method used in this study has been shown to minimise the risk of transcervical contamination if quantitative culture is performed. ${ }^{7} \mathrm{C}$ krusei is known to adhere to vaginal cells in much lesser numbers than $C$ albicans thus explaining its lesser virulence in causing vulvo-vaginitis. ${ }^{8}$

It is possible that pretreatment of the vagina with clotrimazole may affect candida within the endometrium, but it is known that serum levels of clotrimazole after topical vaginal treatment are negligible. ${ }^{9}$ Between $3 \%-10 \%$ of vaginally administered drug is absorbed. Application of a $500 \mathrm{mg}$ pessary results in a peak plasma level of $<0.01 \mu \mathrm{g} / \mathrm{ml}$ suggesting rapid metabolism. This plasma concentration is considered non-fungicidal, mitigating against a systemic effect of vaginally administered clotrimazole. Direct transcervical spread of clotrimazole from vagina to uterus would seem unlikely in view of the physiological barrier of the cervical mucus plug and the flow of cervical secretions downwards from the cervix.

The results of this study lead us to conclude that in cases of recurrent vaginal candidiasis, an endometrial resevoir of candidal species is an unlikely cause.

This study was supported by a grant from Pfizer Ltd.

1 Willcox RR, Willcox JR. Candidiasis. In: Willcox $R R$ Willcox JR, eds. Venereological Medicine. London: Gran McIntyre Ltd, 1982:127-38.

2 Oriel JD, Partridge BM, Denny MJ, Coleman JC. Genital yeast infections. BMF 1972;4:761.

3 Scott JS. Benign Disease of the vagina and vulva. In Whitfield CR, ed. Dewhurst's Textbook of Obstetrics and Gynaecology for Postgraduates, 4th ed. Oxford: Blackwell Scientific Publications, 1986:701-25.

4 Stirrat GM. The lower genital tract. In: Aids to Obstetrics and Gynaecology. Edinburgh: Churchill Livingstone, and Gynaecolo

5 Sweet RL, Gibbs RS. Infectious vulvovaginitis. In Infectious Diseases of the Female Genital Tract. 2nd ed. Baltimore: Williams and Wilkins, 1990:216-28.

6 Report of an International Multicentre Trial. A comparison of single-dose oral fluconazole with 3-day intravaginal clotrimazole in the treatment of vaginal candidiasis. Br f Obstet Gynecol 1989;96:226-32.

7 Eschenbach DA, Rosene K, Tompkins LS, Watkins $H$ Gravett MG. Endometrial culture obtained by a triplelumen method from afebrile and febrile postpartum women. $\mathcal{F}$ Infect Dis 1986;153:1038-45.

8 Sobel ID Vulvovaginal candidiasis In: Holmes KK Mardh P-A, Sparling PF, eds. Sexually Transmitted Diseases. 2nd ed. New York: McGraw Hill, 1990: Diseases.

9 Ritter W, Patzschke K, Kause V, Stettendorf $S$ Fundamentals of vaginal treatment with clotrimazole. Chemotherapy 1982;28:37-42. 